\title{
Utilização de Metodologia Ativa de Ensino nas Aulas Práticas de Anatomia
}

\author{
Cesar Alexandre Fabrega Carvalho \\ Departamento de Anatomia do Instituto de Ciências Biomédicas da Universidade de São Paulo e \\ Departamento de Morfologia e Patologia Básica da Faculdade de Medicina de Jundiaí
}

* Autor para correspondência: carvalhocaf@usp.br

\begin{abstract}
RESUMO
As estratégias pedagógicas adotadas na prática do ensino da Anatomia têm reduzido o processo de aprendizagem à simples memorização da Nomina Anatômica. O objetivo do presente trabalho foi o de avaliar a eficácia do emprego de metodologia ativa de ensino nas aulas práticas de Anatomia. Utilizaram-se situações-problema para serem resolvidas em equipe formada por sorteio. Cada equipe recebeu um formulário contendo: enunciados de casos, questões e nomes de estruturas anatômicas. Um tempo foi estabelecido para a resolução dos casos. Ao término de tal período, as equipes apresentaram as respostas de cada situação-problema com mediação do professor. A metodologia em questão tem sido adotada há cinco anos, nos diferentes cursos da área da Saúde. Verificou-se ao longo desse período maior motivação dos estudantes na busca ativa do aprendizado, maior índice de presença em aulas, além do desenvolvimento do espírito de equipe. Em conclusão, a metodologia aplicada nas aulas práticas de Anatomia promoveu resultados positivos em relação às avaliações e, principalmente, na aprendizagem efetiva do conteúdo pelo estudante.
\end{abstract}

Palavras-Chave: Anatomia Humana; Metodologia Ativa de Ensino; Aprendizagem.

\begin{abstract}
The pedagogical strategies adopted in the practice of the teaching of Anatomy have reduced the learning process to the simple memorization of the Anatomical Nomina. The aim of the present study was to evaluate the effectiveness of the use of active teaching methodology in the practical classes of Anatomy. Problems situations were used to be solved in team formed at random. Each team received a form containing: case statements, questions and names of anatomical structures. A time was set for the resolution of cases. At the end of the time the teams expressed the answers of each problem situation with the professor's mediation. The methodology presented has been adopted five years ago in the different courses in the health area. Throughout this period, there was a greater motivation of the students in the active search for learning, a higher rate of presence in classes, and the development of team spirit. In conclusion, the methodology applied in the practical classes of Anatomy promoted positive results in relation to the evaluations and, mainly, in the effective learning of the content by the student.
\end{abstract}

Keywords: Human Anatomy; Active Teaching Methodology; Learning.

\section{Introdução}

O aprendizado da anatomia humana, até a primeira metade do século passado, baseava-se, essencialmente, na prática de dissecações, que ao longo do tempo foi se adaptando por múltiplas razões, inclusive pela diminuição da disponibilidade de cadáveres. Tais adaptações provocaram distorções no Processo de Ensino da Anatomia que, em grande parte, limitou-se à apresentação e ao reconhecimento de espécimes já dissecados, enfatizando a memorização dos nomes científicos das partes específicas do corpo humano - Nomina Anatômica (EDLER \& FRÓES DA FONSECA, 2005, pp. 6-26)

A desmotivação do estudante, especialmente nas duas últimas décadas, foi crescente e, em grande parte, deveu-se à falta de sentido em decorar nomes de forma desvinculada da futura prática profissional. Tal distorção provocou também uma percepção negativa do professor de Anatomia diante de sua prática de ensino (FORNAZIERO \& GIL, 2003, pp. 141-146). 
Os conhecimentos anatômicos são imprescindíveis para o profissional da área de saúde que, por toda a sua vida, lidará com o corpo humano. A Anatomia constitui a base para o entendimento de outras disciplinas fundamentais como a Fisiologia, a Patologia, a Semiologia, a Propedêutica e a Clínica, entre outras (TURNEY, 2007, pp. 104-107; TAVANO, 2011).

Entretanto, muitas vezes, a percepção do estudante sobre a real importância da Anatomia ocorre mais tarde, diante de situações da prática profissional, especialmente daquelas que exigem o conhecimento espacial do corpo humano, desde procedimentos rotineiros, como uma punção venosa ou liquórica, a inserção de um cateter central e exame físico, até procedimentos cirúrgicos mais complexos (FONTANELLES, 2006, pp. 11-12).

Diante disso, o presente trabalho teve como objetivos: relatar a experiência vivenciada nas aulas práticas de Anatomia, a partir da aplicação de metodologia ativa de ensino nos cursos da área de Saúde; evidenciar a importância da quebra de paradigmas para favorecer uma aprendizagem efetiva e aplicada dos estudantes, sobre a anatomia humana.

\section{Relato de Experiência}

O método desenvolvido consiste de duas etapas. A primeira ocorre em sala de aula, com a apresentação de casos clínicos (situações-problema), e a segunda tem lugar no laboratório de Anatomia, quando os estudantes recebem formulários (figura 1) contendo os referidos casos e uma lista numerada de estruturas anatômicas correspondentes às peças anatômicas (figura 2), para auxiliar na resolução dos problemas. Nessa etapa, os espécimes anatômicos deixam de ser simples partes do corpo a se memorizarem, passando a elementos-chave na resolução dos problemas propostos.

A resolução dos desafios se dá pelas equipes formadas aleatoriamente, as quais, de imediato, iniciam a troca de informações, para resolver o caso. Para cada desafio, há uma estação e um tempo determinado, que se dá na forma de gincana até que os casos propostos sejam resolvidos.
Em seguida, o professor recolhe a lista numerada de estruturas, e um intervalo de tempo é cedido. No segundo momento dessa etapa, as equipes recebem outro formulário numerado, mas sem os nomes das estruturas anatômicas, para serem preenchidos, também no sistema de gincana.

Finalmente, é estimulada a declaração das respostas sobre a resolução das situações-problema de cada grupo. As discussões são mediadas pelo professor que, após ampla discussão, apresenta as respostas mais plausíveis, suas justificativas, e conclui a aula.

\section{Discussão}

A utilização da metodologia ativa apresentada neste trabalho tem se mostrado eficaz nos processos de ensino e de aprendizagem da Anatomia. A prática de ensino foi baseada em estratégias construídas a partir do projeto pedagógico do curso e da expectativa em relação às competências do egresso, ao contrário do que se fazia anteriormente, quando os conteúdos ministrados eram réplicas do praticado ao longo de décadas. A anatomia pela anatomia, sem aplicação ou relevância do que se ensinava para a prática profissional.

A metodologia permitiu reavaliar nossas certezas, rever nossas posturas e concluir que, definitivamente, o nosso papel, enquanto professores de Anatomia, deve ser o de um facilitador e não mais de um depositante de informações, muitas vezes sem significado prático ou de relevância (FREIRE, 1987).

Os processos de ensino e de aprendizagem devem ser um conjunto de atividades articuladas nas quais os diferentes atores compartilham, cada vez mais, parcelas de responsabilidade e comprometimento (SANTOS, 2005). Para isso, é essencial a superação da concepção bancária, na qual se faz o depósito de conteúdos e o outro é obrigado a memorizá-los, ou da prática licenciosa, sem limite, espontaneísta, de indivíduos entregues a si mesmos e à própria sorte, num vazio de quem faz e desfaz a seu gosto (CYRINO \& TORALLES-PEREIRA, 2004, pp. 780-788). FREIRE (1987) ainda destaca que a educação deve ser libertadora, reflexiva e capaz de 
Departamento de Anatomia ICB-USP

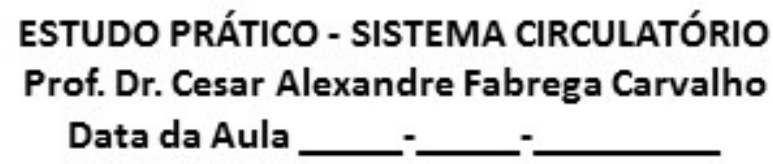

\section{Formulário 1}

\section{Equipe Número}

Nomes:

Problema 1

Paciente de 55 anos chega ao hospital com fortes dores na região retroesternal, suspeitando de infarto no miocárdio. Ao avaliar o traçado eletrocardiográfico nota-se que a onda " $\mathrm{p}$ " está alterada. Realiza-se o exame de cateterismo e verifica-se o comprometimento do aporte sanguineo provocado por uma placa de ateroma. Considere as informações e preencha os campos abaixo.

a) Observar no coração as artérias indicadas pelos alfinetes e marcar a alternativa que o grupo acredita ser aquela, cuja a luz, está reduzida pela placa de ateroma?

\begin{tabular}{l|l|l|l|}
1 & 2 & 3 & 4
\end{tabular}

b) Procure na lista enumerada os nomes das artérias indicadas acima e reescreva-os nos respectivos campos abaixo

\begin{tabular}{|l|l|l|l|}
\hline $1-$ & $2-$ & $3-$ & $4-$ \\
\hline
\end{tabular}

Justificar a escolha da alternativa utilizando os nomes das artérias de modo correto

\section{Formulário 2}

Equipe Número

Nomes:

\begin{tabular}{|c|c|c|}
\hline \multicolumn{2}{|c|}{$\begin{array}{c}\text { Escreva o Nome da Estrutura Anatômica } \\
\text { Indicada pelo Alfinete Numerado }\end{array}$} & $\begin{array}{c}\text { Escreva a Principal Função Associada às } \\
\text { Estruturas Anatômicas }\end{array}$ \\
\hline 1 & & \\
\hline 2 & & \\
\hline 3 & & \\
\hline 4 & & \\
\hline 5 & & \\
\hline 6 & & \\
\hline
\end{tabular}

Figura 1 - Formulários utilizados nas aulas práticas e nas avaliações. 


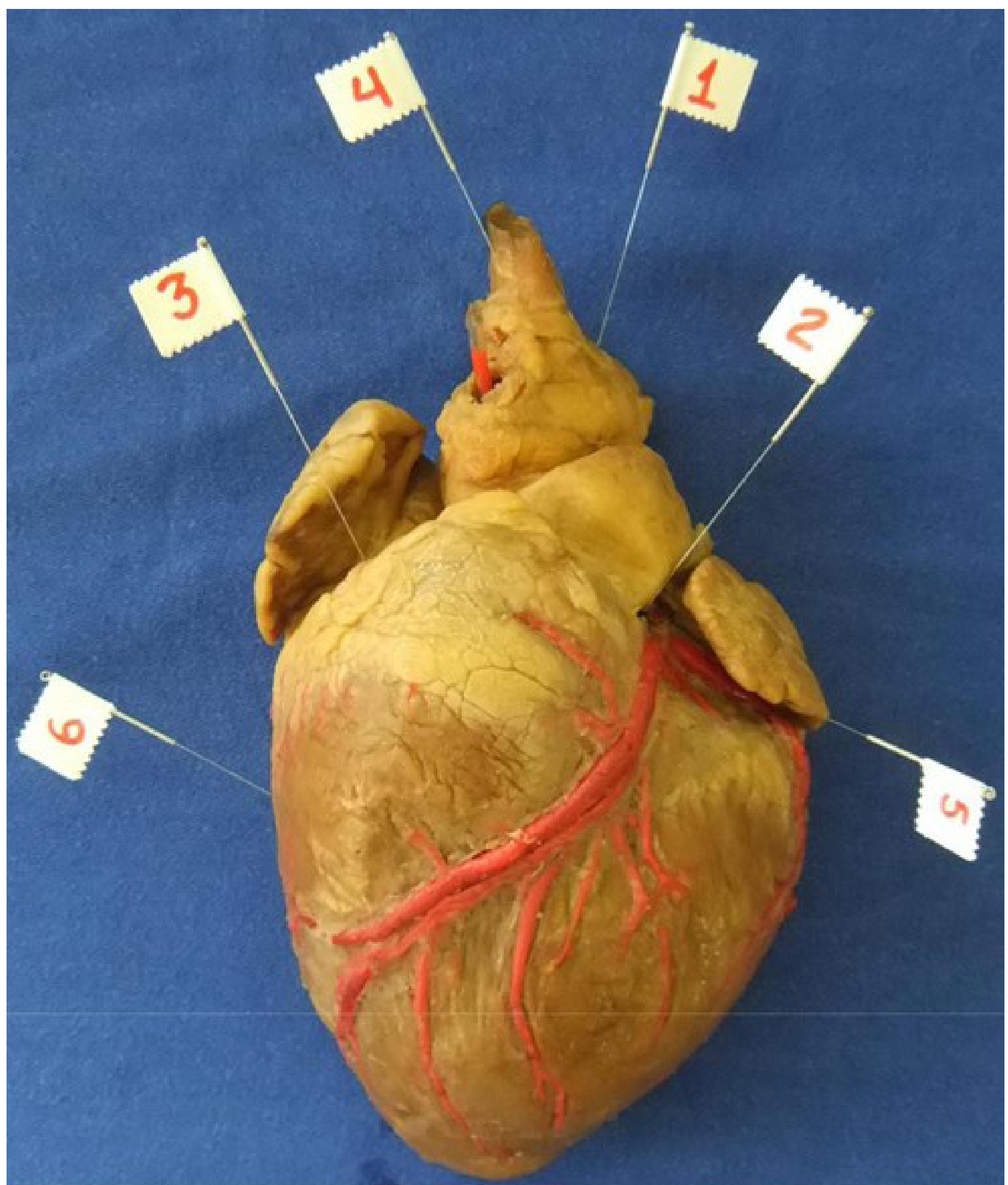

Figura 2 - Coração em vista esternocostal. As artérias coronárias foram injetadas com látex e depois dissecadas. Notar as agulhas de acupuntura numeradas indicando os diferentes ramos das artérias coronárias que poderiam estar associadas ao caso clínico. (Preparação: Professor Cesar). 1. Arco da Aorta, 2. Artéria Coronária Esquerda, 3. Artéria Coronária Direita. 4. Artéria Carótida Comum Esquerda, 5. Ramo Circunflexo da A. Coronária Esquerda, 6. Ramo Marginal da A. Coronária Direita.

produzir uma nova lógica na compreensão do mundo: crítica, criativa, responsável e comprometida.

Os estudantes, literalmente, incorporaram o espírito de equipe, demonstraram motivação e gran- de interesse pelas aulas, sentiram-se mais livres e, portanto, mais questionadores, além de responsáveis e comprometidos. Esses atributos, sem dúvida, favoreceram desempenhos altamente satisfatórios 
nas avaliações, com médias e desvios- padrão significativamente melhores quando comparados aos das turmas ensinadas pelo método anterior. Assim sendo, a metodologia empregada de fato resultou no desenvolvimento de um ambiente propício para a manifestação das qualidades esperadas, conforme lembra Freire. A metodologia foi capaz de manter a motivação dos estudantes, na busca ativa do aprendizado, ao longo do curso, além de um aprendizado significativo de Anatomia Humana.

\section{Referências Bibliográficas}

GYRINO, E. G.; TORALLES-PEREIRA, M. L. "Trabalhando com Estratégias de Ensino-Aprendizagem por Descoberta na Área de Saúde: Problematização e Aprendizagem Baseada em Problemas". Cad. Saúde Pública, vol. 20, n. 3, pp. 780-788, 2004.

EDLER, Flávio Coelho \& FRÓES DA FONSECA, Maria Rachel. "Coletânea de Artigos Originais e Publicados nos Boletins Informativos da Abem". Cadernos da Abem - História da Educaşão Médica, vol. 2, pp. 6-26, 2002.

FONTANELLES, M. P.; CARVALHO, R.
M.; PEREIRA, N.; JORGE, S. M. \& MAIA, M. F. "Anatomical Dictionary of Structures and Terms: Version Bilingue Portuguese/English Using Multimedia in CD-ROM". Revista Paraense de Medicina, vol. 20, n. 2, pp. 1-12, 2006.

FORNAZIERO, C. C. \& GIL, G. R. R. "Novas Tecnologias Aplicadas ao Ensino da Anatomia Humana". ver. Bras. Edu.c Med., vol. 27, n. 2, pp. 141-146, 2003.

FREIRE, P. Pedagogia do Oprimido. 17 ed. São Paulo: Paz e Terra, 1987.

SANTOS, S. S. A Integraşão do Ciclo Básico com o Profissional no Curso de Graduação em Medicina: uma Resistência Exemplar. Rio de Janeiro: Papel \& Virtual; Teresópolis: Feso, 2005.

TURNEY, B. W. Anatomy in a Modern Medical Curriculum. Ann R Coll Surg Engl., vol. 89, n. 2, pp. 104-107, 2007.

TAVANO P. T. Onde a Morte se Compraz em Auxiliar a Vida: A Trajetória da Disciplina de Anatomia Humana no Currículo Médico da Primeira Faculdade Oficial de Medicina de São Paulo - O período de Renato Locchi (1937-1955). Dissertação (Mestrado em Educação) Faculdade de Educação da Universidade de São Paulo, 2011. 